\title{
Density Functional Theory Study of the Interaction of 2- Mercaptobenzimidazole and Gold, Palladium and Nickel atoms
}

\author{
Ourida Mahmoudi, 2,3, Tarik Bordjiba ${ }^{2,3 *}$ and Abed Mohamed Affoune ${ }^{3}$ \\ ${ }^{1}$ Departement of Chemistry, Sciences Faculty, Badji-Mokhtar-Annaba University, Box 12, 23000 \\ Annaba, Algeria \\ ${ }^{2}$ Laboratory of Electrical Engineering of Guelma, 8 mai 1945-Guelma University Box 401, 24000 \\ Guelma, Algeria \\ ${ }^{3}$ Process Engineering Department, Sciences and Engineering Faculty, 8 mai 1945-Guelma University, \\ Box 401, 24000 Guelma, Algeria \\ *E-mail: bordjiba_tarik@yahoo.ca
}

doi: $10.20964 / 2016.06 .33$

Received: 29 February 2016 / Accepted: 23 March 2016 / Published: 4 May 2016

The purpose of this work is to study the adsorption of 2-Mercaptobenzimidazole on three different types of atoms: gold, palladium and nickel. The Density Functional Theory Study (DFT) calculations were performed on 2-Mercaptobenzimidazole (2MBI) and three complexes: 2Mercaptobenzimidazole-gold atom (2MBI-Au), 2-Mercaptobenzimidazole-palladium atom (2MBI-Pd) and 2-Mercaptobenzimidazole-nickel atom (2MBI-Ni). The quantum chemical parameters of $2 \mathrm{MBI}$ and the complexes: 2MBI-Au, 2MBI-Pd and 2MBI-Ni, have been calculated. The considered quantum chemical parameters are: lengths bonds, angles bonds, optimization energy, binding energy, Mulliken atomic charges, energies of highest occupied molecular orbital $\left(\mathrm{E}_{\mathrm{HOMO}}\right)$, the lowest unoccupied molecular orbital $\left(\mathrm{E}_{\mathrm{LUMO}}\right)$, the energy difference $(\Delta \mathrm{E})$ between $\mathrm{E}_{\mathrm{LUMO}}$ and $\mathrm{E}_{\mathrm{HOMO}}$, chemical hardness $\eta$ and the dipole moment $\mu$. The complexation of $2 \mathrm{MBI}$ with $\mathrm{Au}, \mathrm{Pd}$ and $\mathrm{Ni}$ atoms modifies the quantum chemical parameters of the organic molecule. This study reveals that gold atom bonds with $2 \mathrm{MBI}$ molecule via sulfur atom, however, the palladium and nickel atoms bond with 2MBI molecule via nitrogen atom. The results of the present work give a new insight on self assembly of 2Mercaptobenzimidazole molecules at metal surface and provide significant information for fundamental and applied electrochemistry.

Keywords: 2-mercaptobenzimidazole, self-assembly, Adsorption, Density Functional Theory (DFT), Energy gap, chemical hardness $\eta$, Dipole moment, Theoretical calculation, Gold, Palladium, Nickel. 


\section{FULL TEXT}

(C) 2016 The Authors. Published by ESG (www.electrochemsci.org). This article is an open access article distributed under the terms and conditions of the Creative Commons Attribution license (http://creativecommons.org/licenses/by/4.0/). 